Pontifícia Universidade Católica $_{\text {mat }}$

Jaci de Fátima Souza Candiotto

A Teologia feminista e seus giros hermenêuticos:
Reinterpretações de Deus, do ser humano e da criação

Tese de doutorado

Tese apresentada ao Programa de Pós-graduação em Teologia do Centro de Teologia e Ciências Humanas da PUC-Rio como requisito parcial para obtenção do título de doutor em Teologia.

Orientadora: Prof $\stackrel{a}{\text {. Ana Maria Tepedino }}$

Rio de Janeiro

Abril de 2012 


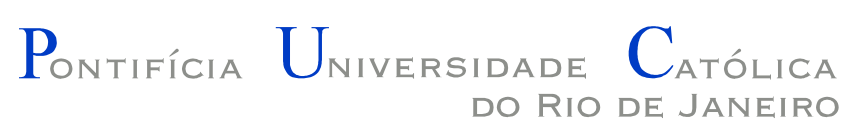

Jaci de Fátima Souza Candiotto

\title{
A Teologia feminista e seus giros hermenêuticos: Reinterpretações de Deus, do ser humano e da criação
}

Tese de doutorado

Tese apresentada como requisito parcial para obtenção do grau de Doutor pelo Programa de Pós-Graduação em Teologia do Centro de Teologia e Ciências Humanas da PUC-Rio. Aprovada pela Comissão Examinadora abaixo assinada.

\author{
Profa. Ana Maria de Azevedo Lopes Tepedino \\ Orientadora \\ Departamento de Teologia - PUC-Rio
}

Profa. Maria Clara Bingemer Departamento de Teologia - PUC-Rio

Profa. Maria Tereza P. Cavalcanti Departamento de Teologia - PUC-Rio

Profa. Mercedes Lopes Centro de Estudos Bíblicos

Profa. Clélia Peretti Curso de Teologia - PUCPR

Profa. Denise Berruezo Portinari

Coordenador Setorial de Pós-Graduação e Pesquisa do Centro de Teologia e ciências humanas - PUC-Rio. 
Rio de Janeiro, 13 de abril de 2012

Todos os direitos reservados. É proibida a reprodução total ou parcial do trabalho sem autorização da universidade, da autora e da orientadora.

\section{Jaci de Fátima Souza Candiotto}

Graduou-se em Filosofia pela Pontifícia Universidade Católica do Paraná em 1991. Graduou-se em Teologia pelo Studium Theologicum (Curitiba) em 1995. Cursou Mestrado em Educação pela Pontifícia Universidade Católica do Paraná em 2002 e Mestrado em Teologia pela Pontifícia Universidade Católica do Rio de Janeiro em 2008. Participou em vários Congressos na área de Educação, da Teologia. Tem experiência nas áreas de Filosofia, Educação e Teologia. Atualmente é professora do Curso de Teologia da Pontifícia Universidade Católica do Paraná.

Ficha Catalográfica

Candiotto, Jaci de Fátima Souza

A teologia feminista e seus giros hermenêuticos: reinterpretações de Deus, do ser humano e da criação / Jaci de Fátima Souza Candiotto; orientadora: Ana Maria Tepedino. -2012.

$297 \mathrm{f.} ; 30 \mathrm{~cm}$

Tese (doutorado)-Pontifícia Universidade Católica do Rio de Janeiro, Departamento de Teologia, 2012.

Inclui bibliografia

1. Teologia - Teses. 2. Teologia feminista. 3. Patriarcado. 4. Hermenêutica. 5. Gênero. 6. Ecofeminismo. 7. Mulheres. 8. Igreja. I. Tepedino, Ana Maria. II. Pontifícia Universidade Católica do Rio de Janeiro. Departamento de Teologia. III. Título.

CDD: 200 
Ao esposo Cesar,

Aos filhinhos Marcelo e Sophia. 


\section{Agradecimentos}

A Deus, fonte e sustento da vida plena para todos!

À PUC-Rio, pela bolsa de estudos concedida.

À minha orientadora Prof ${ }^{a}$. Ana Maria Tepedino, que fez comigo este caminho de pesquisa como verdadeira mestra que espera do/a discípulo/a mais do que ele/a pensa poder estar ao seu alcance.

Às professoras e aos professores da Pós-graduação em Teologia que, além das aulas, foram inspiradores para a realização da presente pesquisa. Especialmente às professoras Maria Clara Bingemer, Tereza Cavalcanti e Ana Maria Tepedino, avaliadoras da prébanca de defesa.

Ao Prof. Dr. Mário Antonio Sanches da PUC-PR, pelo incentivo, apoio e cooperação.

Às secretárias da Pós-graduação, Denise e Sérgio, pelo atendimento eficiente, solícito e compreensivo.

Às duas mulheres especiais Lucilla e Maria Ivonir, por sua sabedoria de vida e por estarem diretamente ligadas à minha existência respectivamente nas condições de mulher-filha e mulher-esposa.

Aos meus filhos Marcelo e Sophia, que nasceram durante meu mestrado e doutorado, respectivamente.

Ao meu esposo Cesar, com quem partilho a experiência do amor verdadeiro, agradeço a paciência e a colaboração, sendo muitas vezes pai/mãe nas minhas ausências. 


\section{Resumo}

Candiotto, Jaci de Fátima Souza. Tepedino, Ana Maria. A Teologia feminista e seus giros hermenêuticos: Reinterpretações de Deus, do ser humano e da criação. Rio de Janeiro, 2012, 297p. Tese de doutorado Departamento de Teologia, Pontifícia Universidade Católica do Rio de Janeiro.

A Teologia feminista e seus giros hermenêuticos: Reinterpretações de Deus, do ser humano e da criação. O propósito desta tese é mostrar que a teologia, se analisada a partir da hermenêutica feminista bíblico-cristã e seus desdobramentos sistemáticos, tem condições de propor uma imagem de Deus compatível com os desafios de nossa época, diante da prevalência de sua identificação masculina sedimentada pelo patriarcado. Além disso, ela realiza uma releitura da antropologia teológica e da teologia da criação a partir das mediações de gênero e do ecofeminismo, capazes de questionar os dualismos hierárquicos entre Deus/mundo, homens/mulheres, seres humanos/demais seres. A insistência em relações de reciprocidade que respeitem as diferenças, bem como na prática eclesial do discipulado de iguais por parte de mulheres e homens, é imprescindível para reavaliar nossa inserção no mundo. Por sua vez, relações harmoniosas entre seres humanos e natureza resultarão em imagens de Deus menos distantes do mundo, e em um mundo menos vazio de Deus. A teologia feminista bíblico-cristã, portanto, apresenta uma contribuição inconteste para o conjunto da teologia, ao imaginar o mundo como corpo de Deus; e Deus, em sua presença no mundo.

\section{Palavras-chave}

Teologia feminista; Patriarcado; Hermenêutica; Gênero; Ecofeminismo; Mulheres; Igreja; Kénosis; Imagens de Deus; Antropologia teológica. 


\section{Abstract}

Candiotto, Jaci de Fátima Souza. Tepedino, Ana Maria (Advisor). Feminist Theology and its hermeneutics turns: Reinterpretations of God, the Human beings and the Creation. Rio de Janeiro, 2012, 297p. Doctoral Thesis - Departamento de Teologia, Pontifícia Universidade Católica do Rio de Janeiro.

Feminist Theology and its hermeneutic turns: Reinterpretations of God, the Human beings and the Creation. The purpose of present thesis is to show that theology, if analyzed from the biblical-Christian feminist hermeneutics and its systematic unfoldings, is able to propose an integrated image of God, given the prevalence of male identification sedimented by patriarchy. In addition, it performs a re-reading of theological anthropology and theology of creation from the mediations of gender and ecofeminism, able to question the hierarchical dualisms between God/world, men/women, human/ others beings. The insistence on reciprocal relationships that respect the differences as well as on Church's practice of discipleship of equals by men and women, it is essential to reassess our place in the world. In turn, harmonious relationships between humans and nature will result in images of God, the less distant from the world, and in a world less empty of God. The biblical-Christian feminist theology, therefore, presents an undeniable contribution to the whole of theology, to imagine the world as the body of God, and God in his presence in the world.

\section{Keywords}

Feminist theology; Patriarchy; Hermeneutics; Gender; Ecofeminism; Women; Church; Kenosis; Images of God; Theological anthropology. 


\section{SUMÁRIO}

1. Introdução

2. Mulheres, Teologia e Libertação: uma trajetória histórica

2.1. Movimento de mulheres, feminismo e comunidades eclesiais

2.1.1. Os feminismos e sua influência no cristianismo e nos movimentos de mulheres da América Latina

2.2. Movimento de mulheres e Comunidades Eclesiais de Base

2.3. A leitura popular da Bíblia 47

2.4. O surgimento da teologia na ótica das mulheres 53

2.4.1. Teologia da Libertação e Teologia na ótica das mulheres 58

2.4.2. A teologia feminista e a mediação de gênero 67

2.4.3. Uma perspectiva de teologia crítica da libertação 77

3. A teologia feminista e seus giros hermenêuticos 84

3.1. Introdução 84

3.2. Hermenêutica teológica e hermenêutica teológica feminista 87

3.3. Perspectivas hermenêuticas feministas 92

3.3.1. Uma Hermenêutica da experiência 95

3.3.2. Uma hermenêutica do lugar social e da dominação 105

3.3.3. Uma hermenêutica da suspeita 110

3.3.4. Uma hermenêutica da relembrança e da reconstrução: a revisitação das comunidades paulinas $\quad 124$

3.4. Por uma lógica da igualdade entre mulheres e homens 133

3.5. Considerações sobre o Capítulo 2

4. Perspectivas integradoras da teologia feminista: sobre a problemática da nomeação divina 141

4.1. Introdução 141

4.2. Deus como pai e o processo de despatriarcalização das relações humanas

4.3. Uma ressignificação da compreensão de Deus:

A contribuição da teologia metafórica de Sallie McFague 
4.3.1. Deus como Rei e Senhor: o modelo monárquico e kyriárquico 154

4.3.2. Deus como pai/mãe do mundo 158

4.3.3. Deus como amante do mundo 164

4.3.4. Deus como amigo do mundo 171

4.3.5. Considerações sobre a teologia de McFague 175

4.4. Perspectivas kenóticas de Deus 177

4.4.1. Os limites do modelo racional de Deus no secularismo atual 178

4.4.2. A experiência do sofrimento como limite de um Deus Todo-poderoso 184

4.4.3. A Criação como Kénosis trinitária $\quad 187$

4.4.4. Kénosis, cristologia e teologia feminista 194

4.5. Considerações sobre o Capítulo $3 \quad 199$

5. Ressignificações do ser humano e suas relações com a natureza na teologia feminista e ecofeminista 203

5.1. Introdução 203

5.2. A interpretação dos relatos da criação pela teologia feminista 211

5.3. Desdobramentos antropológicos da teologia da criação 221

5.3.1. Novos olhares a partir das relações de gênero 227

5.4. As mulheres, o pecado e a salvação 231

5.5. A reavaliação das relações entre seres humanos e natureza $\quad 244$

5.5.1. Ecofeminismo simbólico-cultural 247

5.5.1.1. Ecofeminismo simbólico-essencialista 247

5.5.1.2 Ecofeminismo simbólico-construcionista 252

5.5.2 Ecofeminismo socioeconômico 256

5.6. Considerações sobre o Capítulo 262

6. Considerações finais 266

7. Referências bibliográficas 